\title{
Imitation in Language Development: If, When, and Why ${ }^{1}$
}

\author{
Lois Bloom, Lois Hood, and Patsy Lightbown
}

CitATiOn: Bloom, L., Hood, L., and Lightbown, P. (1974). Cognitive Psychology, 6, 380-420. Reprinted in Bloom, L. (1991). Language development from two to three, New York: Cambridge University, pp. 399-432.

\begin{abstract}
In order to explore the function of imitation for first language learning, imitative and spontaneous utterances were compared in the naturalistic speech of six children in the course of their development from single-word utterances (when mean length of utterance was essentially 1.0) to the emergence of grammar (when mean length of utterance approached 2.0). The relative extent of imitation and the lexical and the grammatical variation between imitative and spontaneous speech were determined. There were inter-subject differences in the extent of imitation, but each child was consistent in the tendency to imitate or not to imitate across time. For those children who imitated, there were both lexical and grammatical differences in imitative and spontaneous speech, and a developmental shift from imitative to spontaneous use of particular words and semantic-syntactic relations between words. The results are discussed as evidence of an active processing of model utterances relative to the contexts in which they occur for information for language learning.
\end{abstract}

When children say something in response to what someone else says, they can either repeat what they hear or say something that is more or less related to it. The two possibilities, to imitate or not to imitate, are represented in the following speech events from two different children:

(1) P (age 21 months, 1 week):

(Peter opening cover of tape recorder)

open/open/open.

Did you open it?

(Peter watching the tape recorder)

open it.

Did you open the tape recorder?

(Peter still watching the tape recorder)

tape recorder.

(2) A (age 19 months, 2 weeks):

(Allison jumped up, almost hitting her head on overhead microphone; the microphones in the studio had been placed and adjusted by the cameraman before videotaping began; Allison touches the microphone, turns to Mommy)

man.

Man. That's the microphone. That's the microphone.

(Allison pointing to another microphone on lavaliere around Mommy's neck)

Yeah, Mommy has a microphone.

(Allison looks at overhead microphone)

That's another microphone.

(Allison still looking at overhead microphone)

man.

1This study was supported by Research Grant HD o3828 from the National Institute of Child Health and Development, and Fellowship F1-MH-30,001 from the National Institute of Mental Health, United States Public Health Service, to Lois Bloom. The study was published originally in Cognitive Psychology, 6, 380-420; reprinted in Bloom, L. (1991). Language development from two to three, New York: Cambridge University, pp. 399-432; and reformatted for this digital version with slight changes in organization and minor text editing. 
In the two situations, "tape recorder" and "microphone" were relatively unfamiliar. Peter had not seen tape recorders before; Allison had not seen a microphone since the first video session three months earlier. Peter repeated the word he did not know, whereas Allison named something that was associated with the word she did not know. Both children were processing information about language. In order to determine whether or not imitation is important for processing speech relative to the events to which it refers, it is necessary to determine the extent to which children imitate the speech they hear, when imitation occurs if it occurs, and why it occurs. This study described the extent to which imitation occurred in the speech of six children and explored the function of imitation for lexical and grammatical learning in their early language development.

There has always been considerable disagreement about the importance of imitation for language development. One prevailing assumption has been that children need to repeat the speech that they hear in order to learn it. For example, according to Jespersen, "One thing which plays a great role in children's acquisition of language, and especially in their early attempts to form sentences, is Echoism: the fact that children echo what is said to them" (1922, p. 135). Kirkpatrick (1909) and others believed that children are virtually compelled to imitate and that they imitate not only what they themselves have seen or done previously but also totally novel behavior. Bloch (1921), Guillaume (1926/1968), Lewis (1951), and others described a critical stage of imitation that comes between the stage of comprehension and the beginning of speech. However, Fraser, Bellugi, and Brown (1963) concluded from an experimental study of elicited imitation that imitation preceded comprehension in development, and there were early observers, for example, Meumann (1903) and Thorndike (1913), who discounted the importance of imitation for language development altogether.

The behaviorist view of language learning would expect new behaviors to be imitated before they can be incorporated into an individual's repertoire of behaviors, for example, for example, Mowrer (1960), Jenkins and Palermo (1964), and Staats (1971). In 1941, Jakobson (1968 translation) pointed out the contradiction between behaviorist views of language learning that emphasized the importance of imitation on the one hand and the notion of creativity in rationalist accounts of the nature of language on the other. The contradiction was elaborated by Chomsky (1959) and in recent debates about theories of language development (see, for example, the papers and discussions in Bellugi \& Brown, 1964; Dixon \& Horton, 1968; Slobin, 1971; Smith \& Miller, 1966). If the child's task is to discover the rules of grammar that make it possible to speak and understand sentences never spoken or heard before, then imitating a sample of utterances would not be very helpful. In the theory of generative grammar (Chomsky, 1957, 1965), underlying sentence structures and not actual utterances themselves are the relevant data, and underlying structure cannot be imitated (see, for example, McNeill, 1970; Slobin, 1968).

Apparently, only two studies have actually compared children's imitative and spontaneous utterances. ErvinTripp (1964) compared the word order of imitative and spontaneous utterances in the speech of five children; Kemp and Dale (1973) compared grammatical features in the imitative and spontaneous utterances of 30 children. Both studies concluded that imitative speech was not "grammatically progressive," that is, that neither word order nor grammatical features were more advanced in imitative than in spontaneous utterances. However, other impressions have been contradictory. Bloom (1968), Slobin (1968), and Brown (reported in Slobin, 1968) commented that something more than casual observation of children's speech suggests that imitative utterances are different and somewhat beyond the grammatical level represented in spontaneous utterances. Shipley, Smith, and Gleitman (1969) reported that children who were just beginning to use multiword utterances were more likely to repeat a command that contained a nonsense word (for example, "throw ronta ball") than a command with only real words - which led them to conclude that imitation might be a factor in lexical learning.

To the extent that a child must hear a lexical item before using it, one might consider that much of a child's speech is imitative. Leopold (1939-1949, vol. 3), Piaget (1951/1962), and Sinclair (1971) have taken just such a broad view of imitation in development-that as a child incorporates experience in memory, virtually all behavior imitates a model that, if not actually present in the context, would be represented mentally. However, if all behavior in the young child is imitative, then the task of explaining behavior remains, and imitation loses considerable force as a process that might contribute to development. In order to explore the function of imitation as a process in language development, it was necessary to define imitation in a way that made it possible to examine the developmental relationship between behaviors that were and were not imitative. 
For the purpose of this study, only behavior that followed an actual model was considered imitative. An utterance was imitative (1) if it occurred in a natural situation (that is, without the child's being asked or prompted to imitate), (2) if it repeated all or part of a preceding model utterance from someone else, (3) if it did not add to or change the model other than to reduce it by leaving something out, and (4) if no more than five utterances (from the child or others) intervened after the model. The arbitrary limit of five utterances was chosen as intuitively reasonable for establishing an imitative utterance as one that occurred in the context of the model. All other utterances were considered spontaneous. ${ }^{2}$

\section{SUBJECTS AND PROCEDURES}

The study focused on the period of language development in which children progress from using only one word at a time (when mean length of utterance is essentially 1.0) to the emergence of grammar and the use of structured speech (when mean length of utterance approaches 2.0).

Data were obtained from six children in this developmental period from single words to syntax. They were born in the 1960s, the first-born children of white, college-educated parents who lived in university communities in New York City. Their parents were native speakers of American English and their mothers were their primary caregivers. They were chosen as subjects with these qualifications in what turned out to be, in retrospect, a naive effort to come up with a 'homogeneous' population. Since parent education, birth order, and economic differences among children had been found to be sources of individual differences in speech and language in other studies, these were the minimal 'controls' that seemed feasible to ensure that the children would be similar in their language learning. ${ }^{3}$

Five of the children-Eric, Gia, Jane, Kathryn, and Peter-were each visited in their homes periodically, and their speech was audio recorded as they interacted primarily with a familiar adult (the investigators) and, less often, with their mothers. Eric, Gia, Jane, and Kathryn were visited approximately every six weeks, for eight hours over several days, by Lois Bloom; Peter was visited for approximately six hours every three weeks by Lois Hood and Patsy Lightbown. The visits occurred in the context of their daily activities and informal play. The same or similar toys were brought to all the sessions, for the different children and for each child, in an effort to establish consistency in the home contexts among the children and over time. The observations were audio recorded, and the transcriptions included all speech by child and adult, along with descriptions of nonlinguistic context and behavior. 4

The interactions between the sixth child, Allison, and her mother (Lois Bloom), were video recorded in the audiovisual studio at Teachers College, Columbia University, using the procedures for recording and transcribing described in Bloom (1973, pp. 138-41).

The speech samples that were obtained from the six children are described in Table 1 in terms of length of sessions, age, mean length of utterance (MLU), and numbers of utterances. The data for analysis consisted of more than 17,000 utterances from the six children in the period from age 18 months to 25 months. In Table 1 and throughout this report, the term type refers to a particular utterance, and the term token refers to an instance of

\footnotetext{
${ }^{2}$ Slobin (1968) suggested that the most important function of imitation for language acquisition might be the opportunity for children to imitate adult expansions of their own utterances. Such utterances, which represented less than .01 of the data Slobin examined, were not distinguished from other imitative utterances in the present study. When a child's utterance was expanded or repeated by an adult and the child subsequently repeated the original utterance (either unchanged or reduced), the second utterance was also considered spontaneous.

3 However, see Bloom (1992) for a later appraisal of this decision.

4 The procedures for data collection and transcription are described in greater detail in Bloom (1970, pp. 234-9). See, also, Bloom, Lightbown, and Hood (1975) and conventions for transcription of child language recordings, App. A, in Bloom \& Lahey (1978). The speech samples from Eric, Gia, and Kathryn were collected and transcribed by Lois Bloom. The speech samples from Peter were collected and transcribed by Lois Hood and Patsy Lightbown, who took turns interacting with Peter and taking notes on the situational context and behavior. The transcriptions of the Eric, Gia, Kathryn, and Peter data are stored for access by other researchers in the Special Collections at the Gottesman Memorial Libraries, Teachers College, Columbia University; transcripts of the Allison and Peter data are also part of the CHILDES database, the Child Language Data Exchange System, Carnegie-Mellon University.
} 
Table 1. Summary Description of Speech Samples

\begin{tabular}{|c|c|c|c|c|c|c|c|}
\hline \multirow[b]{3}{*}{$\begin{array}{l}\text { Child, } \\
\text { Time }\end{array}$} & \multicolumn{7}{|c|}{ Number of Utterance Types, Tokens } \\
\hline & \multicolumn{3}{|c|}{ Sample Specifications } & \multirow[b]{2}{*}{$\begin{array}{l}\text { Total } \\
\text { Types }\end{array}$} & \multirow[b]{2}{*}{$\begin{array}{c}\text { Total } \\
\text { Syntactic } \\
\text { Types }\end{array}$} & \multirow[b]{2}{*}{$\begin{array}{l}\text { Average } \\
\text { Types per } \\
\text { Hour }\end{array}$} & \multirow[b]{2}{*}{$\begin{array}{c}\text { Total } \\
\text { Tokens }\end{array}$} \\
\hline & $\begin{array}{l}\text { Length } \\
\text { (hours) }\end{array}$ & $\begin{array}{c}\text { Age } \\
\text { (months, } \\
\text { weeks) }\end{array}$ & $\begin{array}{c}\text { MLU } \\
\text { (morphemes) }\end{array}$ & & & & \\
\hline \multicolumn{8}{|c|}{ 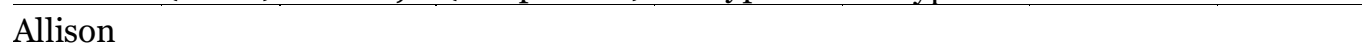 } \\
\hline I & .75 & 16,3 & 1.06 & 49 & 11 & 70 & 283 \\
\hline II & .75 & 19,2 & 1.02 & 67 & 4 & 77 & 321 \\
\hline III & .75 & 20,3 & 1.13 & 118 & 19 & 157 & 379 \\
\hline IV & .75 & 22,0 & 1.73 & 168 & 94 & 224 & 271 \\
\hline \multicolumn{8}{|l|}{ Eric } \\
\hline I & 4 & 19,1 & 1.10 & 96 & 23 & 24 & 296 \\
\hline II & 6 & 20,2 & 1.19 & 179 & 72 & 30 & 615 \\
\hline III & 6.7 & 22,0 & 1.42 & 363 & 176 & 52 & 1043 \\
\hline IV & 3 & 23,2 & 1.69 & 311 & 185 & 104 & 629 \\
\hline \multicolumn{8}{|l|}{ Gia } \\
\hline I & 6.7 & 19,2 & 1.12 & 246 & 83 & 37 & 1045 \\
\hline II & $3 \cdot 3$ & 20,2 & 1.34 & 282 & 149 & 85 & 933 \\
\hline III & 5 & 22,1 & 1.58 & 310 & 197 & 65 & 804 \\
\hline IV & 2.1 & 23,3 & 1.79 & 300 & 194 & 143 & 601 \\
\hline \multicolumn{8}{|l|}{ Jane } \\
\hline I & 5 & 18,2 & 1.29 & 350 & 82 & 70 & 1144 \\
\hline II & 2.5 & 20,0 & 1.27 & 239 & 111 & 96 & 438 \\
\hline \multicolumn{8}{|c|}{ Kathryn } \\
\hline I & 5 & 21,0 & 1.32 & 432 & 226 & 86 & 917 \\
\hline II & 1.7 & 22,3 & 1.89 & 443 & 303 & 260 & 697 \\
\hline III & 1.7 & 24,2 & 2.83 & 474 & 427 & 279 & 642 \\
\hline \multicolumn{8}{|l|}{ Peter } \\
\hline I & 3 & 21,1 & 1.04 & 171 & 21 & 59 & 610 \\
\hline II & 3.5 & $21,31 / 2$ & 1.09 & 136 & 12 & 39 & 418 \\
\hline III & 4.5 & 22,2 & 1.37 & 302 & 119 & 65 & 1052 \\
\hline IV & 4.5 & 23,1 & 1.41 & 363 & 165 & 82 & 1166 \\
\hline $\mathrm{V}$ & 3 & $23,21 / 2$ & 1.33 & 255 & 129 & 83 & 583 \\
\hline VI & 4.5 & 24,1 & 1.75 & 594 & 424 & 133 & 1364 \\
\hline VII & 4.5 & 25,0 & 2.39 & 685 & 551 & 152 & 1195 \\
\hline
\end{tabular}

an utterance type. Thus, the utterance "read that book" was one type that, occurring four times in a sample, had four tokens. As a multiword utterance, "read that book" is also a syntactic utterance type.

Three separate analyses were performed. First, the extent and consistency of imitation were determined for each child in terms of the proportion of utterance types that were imitated in each session. Second, the imitative and spontaneous occurrences of lexical item tokens were observed within each session and across successive sessions. Third, all multiword utterances were examined for regularities in form and meaning in order to determine categories of semantic-syntactic structure. Imitative and spontaneous utterance types in each category were then compared within each session and across successive sessions. 


\section{RESULTS}

\section{The Extent and Consistency of Imitation}

The first concern was to determine whether the children imitated the speech they heard and the extent to which an individual child's tendency to imitate was consistent across time. Following this, imitative and nonimitative utterances were compared for each child in order to determine if there were lexical and structural differences between the two kinds of utterances.

Every utterance in each speech sample was coded as spontaneous or imitative according to the working definitions given earlier. The proportions of utterance types that occurred only spontaneously, only im - itatively, or both spontaneously and imitatively are presented in Table 2.5 It is immediately apparent that there were differences in the extent to which the children imitated. The proportion of imitation in Allison's speech was never more than .06, whereas the proportion of imitation in Peter's speech was always at least .27. For most of the children, the relative tendency to imitate that was observed in the first speech sample continued until MLU reached approximately 2.0 morphemes. ${ }^{6}$ Only Kathryn showed an appreciable change over time. Because the difference between Time I and Time II was so great, Kathryn's speech at Time III was analyzed even though MLU was 2.83 and thus beyond the limits of the study. The lower proportion of imitation at Time II continued at Time III; .09 of the different utterances at Time III were imitative.

There were marked differences then in the extent to which the different children imitated, but each child was consistent in the tendency to imitate across time, as can be seen in Figure 1. According to these results, imitation is not required for learning to talk; two children progressed from single-word utterances to MLU of almost 2.0 without imitating the speech that they heard. Part of the confusion in the early literature about the relative importance of imitation for language development may be attributed to the fact that different observers were watching different children, who did or did not imitate.

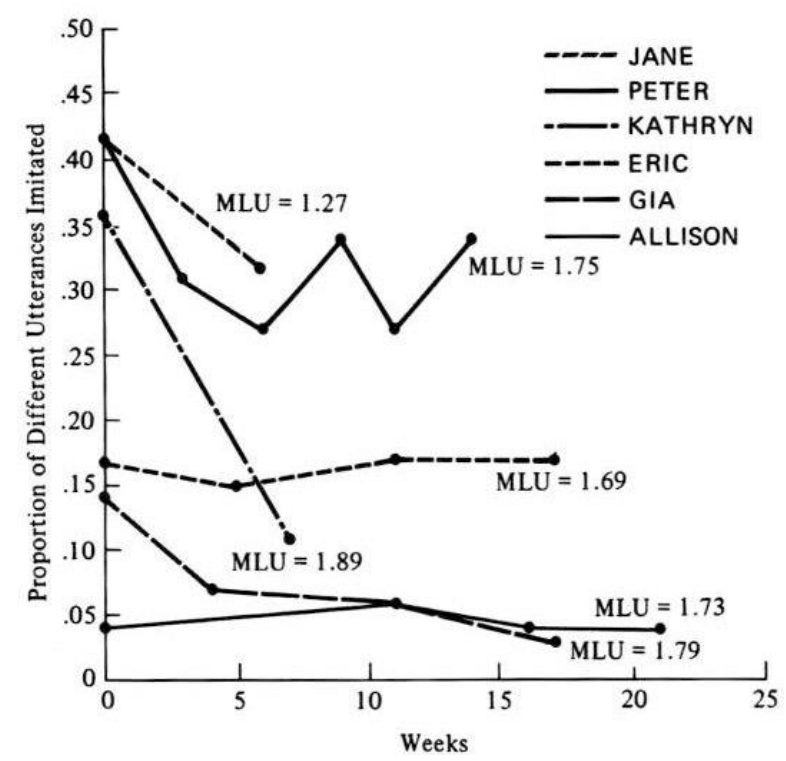

Figure 1. Relative extent of imitation. The proportion of different utterances imitated by each child at each time.

\footnotetext{
5 Utterance types (each different utterance counted as a type), rather than utterance tokens (the number of occurrences of a type), were used for computing these proportions. Item frequency (tokens rather than types) would have resulted in a smaller proportion of imitation in the speech of all the children, because spontaneous utterances occurred more frequently than did imitative utterances.

${ }^{6}$ Except for Jane, whose family moved away following the second recording session.
} 
It might be hypothesized that the nonimitating children were indeed imitating but their imitation was somehow delayed. To explore this possibility, the latency of imitation, in terms of the number of utterances that intervened between the model and its reproduction, was determined for each of the speech samples. The occurrence of imitative utterances was compared in two different conditions: immediate imitation with no intervening utterance, and nonimmediate imitation with at least one but not more than five intervening utterances.

Table 2. Proportion of Utterance Types That Were Only Spontaneous, Only Imitative, or Both Spontaneous and Imitative

\begin{tabular}{|c|c|c|c|c|c|c|}
\hline \multirow{2}{*}{$\begin{array}{l}\text { Child, } \\
\text { Time }\end{array}$} & \multicolumn{3}{|c|}{ All Utterances } & \multicolumn{3}{|c|}{ Only Syntactic Utterances } \\
\hline & Spont & Imit & $\begin{array}{c}\text { Spont + } \\
\text { Imit } \\
\end{array}$ & Spont & Imit & $\begin{array}{c}\text { Spont + } \\
\text { Imit }\end{array}$ \\
\hline \multicolumn{7}{|l|}{ Allison } \\
\hline I & .85 & .04 & .11 & .91 & .09 & - \\
\hline II & .88 & .06 & .06 & 1.00 & - & - \\
\hline III & .92 & .04 & .04 & .95 & - & .05 \\
\hline IV & .94 & .04 & .02 & .98 & .11 & .01 \\
\hline \multicolumn{7}{|l|}{ Eric } \\
\hline I & .71 & .17 & .12 & .69 & .22 & .09 \\
\hline II & .73 & .15 & .12 & .76 & .18 & .06 \\
\hline III & .73 & .17 & .10 & .76 & .21 & .03 \\
\hline IV & .76 & .17 & .07 & .78 & .16 & .06 \\
\hline \multicolumn{7}{|l|}{ Gia } \\
\hline I & .69 & .14 & .17 & .86 & .13 & .01 \\
\hline II & .87 & .07 & .06 & .94 & .05 & .01 \\
\hline III & .88 & .06 & .06 & .92 & .06 & .02 \\
\hline IV & .96 & .04 & - & .97 & .03 & - \\
\hline \multicolumn{7}{|l|}{ Jane } \\
\hline I & .38 & .42 & .20 & .47 & .49 & .04 \\
\hline II & .60 & .32 & .08 & .57 & .41 & .02 \\
\hline \multicolumn{7}{|c|}{ Kathryn } \\
\hline I & .53 & .36 & .11 & .64 & .34 & .02 \\
\hline II & .86 & .11 & .03 & .88 & .11 & .01 \\
\hline \multicolumn{7}{|l|}{ Peter } \\
\hline I & .30 & .42 & .28 & .34 & .57 & .09 \\
\hline II & .48 & .31 & .21 & .59 & .33 & .08 \\
\hline III & .58 & .27 & .15 & .68 & .28 & .04 \\
\hline IV & .54 & .34 & .12 & .57 & .36 & .07 \\
\hline V & .55 & .27 & .07 & .66 & .30 & .04 \\
\hline VI & .58 & .34 & .08 & .57 & .38 & .05 \\
\hline
\end{tabular}

The number of imitative utterance types with token frequency of immediate imitation greater than token frequency of nonimmediate imitation was compared with the number of imitative utterances with nonimmediate frequency greater than immediate frequency. The results of a sign test of the hypothesis that immediate and nonimmediate imitation were equally likely to occur are presented in Table 3. Eric at Time I had 27 imitative utterance types; two of these had equal numbers of immediate and nonimmediate tokens and so were not included in this analysis. Therefore, in the first entry in Table 3 for Eric, for example, frequency of nonimmediate imitation was greater than frequency of immediate imitation for three of the remaining 25 imitative utterance tokens, and immediate imitation was more frequent for 22 had frequency of. The probability of this result given the hypothesis of no difference between immediate and nonimmediate imitation was less than .01. As can be seen in Table 3, there was a significant difference between immediate and nonimmediate imitation $(\mathrm{p}<.01)$ for the 
imitating children (Eric, Jane, Peter, and Kathryn at Time I), whose overall proportion of imitation exceeded .15, and for Gia at Time I when the proportion of imitation was .14. Thus, if these children imitated, they tended to do so immediately, with no utterances intervening between an imitative utterance and its model.

Table 3. Comparison of Immediate and Nonimmediate Imitation

\begin{tabular}{|c|c|c|c|}
\hline \multirow[b]{2}{*}{$\begin{array}{l}\text { Child, } \\
\text { Time }\end{array}$} & \multicolumn{2}{|l|}{ Number of Utterances } & \multirow[b]{2}{*}{$\begin{array}{l}\text { Probability } \\
\text { (less than) }\end{array}$} \\
\hline & $\begin{array}{l}\text { Nonimmediate Greater } \\
\text { than Immediate } \\
\text { Imitation. }\end{array}$ & $\begin{array}{l}\text { Immediate Greater } \\
\text { than Nonimmediate } \\
\text { Imitation }\end{array}$ & \\
\hline \multicolumn{4}{|l|}{ Eric } \\
\hline I & 3 & 22 & .01 \\
\hline II & 11 & 30 & .01 \\
\hline III & 30 & 56 & .01 \\
\hline IV & 22 & 46 & .01 \\
\hline \multicolumn{4}{|l|}{ Jane } \\
\hline I & 8 & 212 & .01 \\
\hline II & 15 & 71 & .01 \\
\hline \multicolumn{4}{|l|}{ Peter } \\
\hline I & 15 & 98 & .01 \\
\hline II & 19 & 52 & .01 \\
\hline III & 40 & 79 & .01 \\
\hline IV & 37 & 118 & .01 \\
\hline $\mathrm{V}$ & 21 & 67 & .01 \\
\hline VI & 39 & 200 & .01 \\
\hline \multicolumn{4}{|c|}{ Kathryn } \\
\hline I & 35 & 122 & .01 \\
\hline II & 35 & 26 & .90 \\
\hline \multicolumn{4}{|l|}{ Gia } \\
\hline I & 22 & 47 & .01 \\
\hline II & 18 & 20 & .44 \\
\hline III & 26 & 12 & .99 \\
\hline IV & 4 & 9 & .14 \\
\hline \multicolumn{4}{|c|}{ Allison } \\
\hline I & 4 & 2 & .89 \\
\hline II & 3 & 3 & .66 \\
\hline III & 6 & 5 & .73 \\
\hline IV & 5 & 3 & .85 \\
\hline
\end{tabular}

However, for the nonimitating children, for whom the overall proportion of imitation was less than .15 (Kathryn at Time II, Allison, and Gia), the difference between immediate and nonimmediate imitation was not significant (except for Gia at Time I). The nonimitating children might have been imitating a model that was further removed than the original five-utterance limit that had been established in defining imitation for this study. In order to test this, the spontaneous utterances from Allison and Gia were classified again after extending to ten the number of utterances that could intervene between the model and its "imitation." In the four samples of Allison's speech, there were only four imitations of a model that occurred with at least five and no more than ten intervening utterances; in $5.6 \mathrm{hr}$ of Gia's speech (the middle third of each sample), there were ten such utterances. If so few imitative utterances occurred within a ten-utterance boundary, there was no reason to expect that there would be imitative utterances beyond that limit. Indeed, it might well be questioned whether such utterances were even imitative at all or whether they might have occurred in any event. 


\section{Comparison of Imitative and Spontaneous Speech}

After it was established that the extent of imitation varied from child to child but remained consistent for each child, we determined how imitation functioned for those children who imitated.

There was a clear division between the utterance types a child imitated and those produced spontaneously, as can be seen in Table 2. Any utterance type which had at least one spontaneous and one imitative token is included in the Spont + Imit column. The number of utterances with both spontaneous and imitative tokens was relatively small for all the children and tended to decrease as MLU increased. When only the syntactic utterances were taken into account, there was an even stronger separation of spontaneous and imitative utterances. Furthermore, many of the utterances included in the Spont + Imit column were high-frequency utterances with many spontaneous tokens and only two or three imitative tokens. For example, at Peter IV, the utterance "in there" occurred 15 times spontaneously and one time imitatively.

\section{Lexical Items}

Different Populations of Words. One function of imitation that has often been suggested is that imitation helps children learn new words. In order to test whether there were two different populations of words in the children's speech at each time, the following procedure was used: The proportion, $p$, of lexical item tokens which were imitated was calculated for each speech sample, both for single-word utterances and words used syntactically. The entries for words used syntactically were found by separating each syntactic utterance into its "word parts" and counting each word separately. For example, the utterance "need another one" was counted as one occurrence each of need, another, and one. The frequency of imitative versus spontaneous tokens of each word which occurred three or more times within a speech sample was compared with the distribution expected on the basis of the binomial expansion using the value of $p$ for that speech sample. If the two-tailed probability of obtaining the observed split between imitative and spontaneous tokens was less than .05, that word was considered to have an extreme split between imitative and spontaneous use. After the number of words with extreme splits was found, a binomial test with $p \leq .05$ was applied to ascertain the likelihood of this number of extreme splits occurring in each sample. For example, for Peter at Time I, of 59 single-word utterances that occurred at least three times, 16 of them split in an extreme way between their spontaneous and imitative frequencies; the probability of observing this many extreme splits was $<.001$. Thus, it was concluded that for this sample there were two populations of single-word utterances, those used spontaneously and those used imitatively.7

The number of words with extreme splits, the total number of words in the analysis (words that occurred three times or more), and the binomial probability of observing a ratio of words with extreme splits to total number of words at least this extreme is presented in Table 4 for those times when the overall proportion of imitation of different utterances was greater than $.15 .{ }^{8}$ As can be seen, for all the samples except Eric at Times I and IV, the results were significant for single-word utterances and/or words used syntactically. This result means that the children tended to use certain words only spontaneously and certain other words only imitatively. However, explanations for the split between imitative and spontaneous occurrence appeared to be different for single-word utterances and words used syntactically.

Single-Word Utterances. The results for single-word utterances were less than convincing at first glance. The number of words that split in an extreme way in their imitative and spontaneous frequencies was not significant for Peter at Times II, V, and VI, nor for Eric at Times I, III, and IV. However, as can be seen in Table 4, for the three samples from Peter that were not significant, the number of words that occurred three or more times so that they could be counted in the analysis was smaller than in those samples where the results were significant.

7 This test was devised by Ruth Gold, Department of Measurement and Statistics, Teachers College, Columbia University.

${ }^{8}$ In those samples in which the proportion of imitation was less than .15 (see Table 2), there were too few imitative occurrences of different words to apply the test. 
Table 4. Summary of Binomial Tests for Two Populations of Words, Imitative and Spontaneous

\begin{tabular}{|c|c|c|c|c|c|c|}
\hline \multirow[b]{2}{*}{$\begin{array}{l}\text { Child, } \\
\text { Time }\end{array}$} & \multicolumn{3}{|c|}{ Single-Word Utterances } & \multicolumn{3}{|c|}{ Words Used Syntactically } \\
\hline & $\begin{array}{l}\text { No. of Words } \\
\text { with Extreme } \\
\text { Splits }\end{array}$ & $\begin{array}{l}\text { No. of } \\
\text { Words in } \\
\text { Analysis }\end{array}$ & $\begin{array}{c}\text { Probability } \\
\text { (less than) }\end{array}$ & $\begin{array}{l}\text { No. of Words } \\
\text { with Extreme } \\
\text { Splits }\end{array}$ & $\begin{array}{l}\text { No. of } \\
\text { Words in } \\
\text { Analysis }\end{array}$ & $\begin{array}{l}\text { Probability } \\
\text { (less than) }\end{array}$ \\
\hline \multicolumn{7}{|l|}{ Eric } \\
\hline I & 1 & 29 & .77 & o & 4 & .83 \\
\hline II & 8 & 44 & .01 & o & 14 & .49 \\
\hline III & 5 & 67 & .24 & 7 & 37 & .01 \\
\hline IV & 3 & 37 & .28 & 2 & 49 & .71 \\
\hline \multicolumn{7}{|l|}{ Peter } \\
\hline I & 16 & 59 & .01 & o & 3 & .86 \\
\hline II & 3 & 44 & .38 & 3 & 7 & .01 \\
\hline III & 23 & 79 & .01 & 6 & 31 & .01 \\
\hline IV & 14 & 89 & .01 & 8 & 52 & .01 \\
\hline V & 4 & 34 & .09 & 7 & 40 & .01 \\
\hline VI & 4 & 49 & .23 & 36 & 113 & .01 \\
\hline \multicolumn{7}{|l|}{ Jane } \\
\hline I & 18 & 101 & .01 & 4 & 14 & .01 \\
\hline II & 5 & 24 & .01 & 2 & 34 & .51 \\
\hline \multicolumn{7}{|c|}{ Kathryn } \\
\hline I & 7 & 64 & .05 & 9 & 69 & .05 \\
\hline
\end{tabular}

Inspection of the data from another perspective-the number of words, regardless of how often they occurred, that split with either no spontaneous and only imitative, or only spontaneous and no imitative occurrence, in the same samples-revealed that Eric and Peter used most words only spontaneously or only imitatively. The proportions of utterances with such splits was at least .75 (and in 4 of the 6 samples at least .85). Thus, it appeared that even in these samples from Peter and Eric, there were indeed two populations of words. A possible explanation of why these samples had so few words with extreme splits was that Peter and Eric simply did not talk very much in these samples, and thus words were not likely to occur frequently, either spontaneously, imitatively, or both (see Table 1). Thus, the test of significance applied to lexical items was just not sensitive enough for data where the sample of speech was relatively small. The test depended on words occurring with high frequency. When there were enough words occurring often enough, the test of significance impressively supported the observation that single-word utterances tended to be either imitative or spontaneous.

Words Used Syntactically. The results for words used syntactically were significant for 8 of the 13 speech samples. The fact that the words the children used spontaneously in syntactic constructions tended to be different from the words used imitatively in syntactic constructions could have two explanations. On the one hand, the differences might be evidence for differentiation of lexical items, as was apparent in the analysis of single-word utterances. On the other hand, when imitating words in a syntactic construction, the children might in fact have been imitating an aspect of the syntax rather than the particular lexical item that was included in the construction. The two kinds of imitation, lexical and grammatical, could not be separated in any analysis that looked at each speech sample separately. For this reason, the samples from Eric and Peter were analyzed in terms of change over time.

Progression from Imitative to Spontaneous Use. If imitation leads to the learning of particular lexical items, then one could expect that those words that were imitative at an early time, if repeated at successive times, would gradually come to be used spontaneously. The hypothesis that a significant proportion of words would progress from mostly imitative occurrence to mostly spontaneous occurrence in the period of study was tested for those children whose overall proportion of imitation was above .15 for more than two sessions. The test was applied for 
each word that (1) occurred in at least two sessions, (2) was imitated at least once and spontaneous at least once, and (3) showed some change across time, either from imitative to spontaneous or spontaneous to imitative use.

Spearman rank-order correlations were found between the session ranks and the observed ranks of the ratio of imitative occurrences to total number of occurrences. This procedure was applied separately to single-word utterances and words used syntactically. The number of sessions in which a target word occurred varied from 2 to 6 for Peter and 2 to 4 for Eric, and the session ranks changed accordingly. If a word occurred in all 6 sessions from Peter, the ranking of sessions was 1, 2, 3, 4, 5, 6; if a word occurred in only 4 of the sessions from Peter, the sessions in which the word occurred were ranked 1, 2, 3, 4. If the ratio of imitative occurrences to total number of occurrences was the same for more than one session, the average of the ranks was used. For example, for the word off, the ratios of imitative tokens to total number of tokens were $1 / 1$ at Time I, $1 / 2$ at II, o/4 at III, and o/3 at IV, for Eric. The session ranking (Times I-IV) was 1, 2, 3, 4, and the observed ratio ranking was 1, 2, 3.5, 3.5, with a resulting rho of .50 . For the word foot, the imitative to total ratios were $0 / 1$ at Time I and $1 / 6$ at Time III, with no occurrences at Times II and IV. The session ranking was 1, 2, and the observed ranking was 2, 1, with a resulting rho of -1.00. A $t$ test was performed on the Spearman rank-order correlations with the null hypothesis that the mean correlation equals zero.

For Peter, there was a significant trend for imitative occurrence of single words to decrease over time. The mean correlation ( $r h o=.323$ ) was significantly different from zero $(t(132)=5.14, p<.001)$. This was not the case for words used syntactically $(r h o=.04, t(102)=.5012)$. For Eric, the reverse was true. For words used syntactically, the mean correlation ( $r h o=.255)$ was significantly different from zero $(t /(51)=2.329, \mathrm{p}<.05)$, while for singleword utterances it was not $(r h o=.047, t /(57)=.429)$. Thus, there was a progression across time as imitation of a particular lexical item decreased while the spontaneous use of that item increased, for single-word utterances in Peter's speech and for multiword utterances in Eric's speech. These differences between Peter and Eric were consistent with the differences between them in the semantic-syntactic functions of imitation in multiword utterances which will be discussed subsequently.

In sum, imitation played a role in the acquisition of new lexical items for the children in this study whose proportion of overall imitation was greater than .15. To the extent that spontaneous use was an index of knowing a word, it could be concluded that the children imitated words that they did not yet know. At any particular time, the children did not imitate words they used spontaneously and did not use spontaneously the words they imitated. Further, there was a clear trend for individual words that were originally imitative to become predominantly spontaneous at later times.

\section{Semantic-Syntactic Structure}

Classifying multiword utterances according to the relations between words resulted in a taxonomy of semanticsyntactic categories that allowed several comparisons to be made. Within one sample of speech from an individual child, both the relative frequency of the different relations and the different utterance forms with these relations could be compared in imitative and spontaneous speech. Successive samples of speech from the same child could then be compared to determine the developmental interaction between imitative and spontaneous speech. In this way it was possible to evaluate the role of imitation for semantic learning (between categories) and syntactic learning (within categories) and to demonstrate that imitation did indeed function in the acquisition of grammar for those children who imitated.

The semantic-syntactic categories were identified by observing the relationship between an utterance and aspects of the child's behavior and the context in which the utterance occurred. Although one cannot know the full semantic intention for any particular utterance, that is, precisely what a child means, there was relatively little difficulty in knowing what the children were talking about. Virtually all the utterances occurred in relation to what the children (and the adults) could see, or in relation to what the children had just done, were doing, or were about to do. The semantic-syntactic categories were dependent on (1) the child's utterance occurring in direct reference to the event that was encoded in the utterance and (2) the inclusion of at least two words in the utterance with an identifiable relationship between them. Adult interpretations were very much context and utterance bound, so that the categories of semantic-syntactic relations were directly derived from the child speech event data rather than being a predetermined system of analysis. 
Four of the categories represented verb relations (whether or not an actual verb was one of the words) that were identified in terms of (1) whether or not movement accompanied an utterance and (2) the goal of movement, when movement occurred. These criteria were contextual and distinguished between action and state relations and between locative and nonlocative actions and states. Of all the relations in the children's speech that expressed action, the overwhelming majority entailed action on an affected object or the goal of a change in location. Such verbs as "get up" and "fall down," which are intransitive in the adult model, were productive as locativeaction verbs in the present study; such intransitive verbs as "turnaround" and "dance," which were categorized as actions (without affected-object), did not occur productively (with productivity defined as five different utterances at a particular time).

For several verbs in each of these categories, one could argue for a different classification based on adult introspection. The verb "get" was an example of the dilemma that sometimes arose in distinguishing between action and locative-action events. One could argue that "get" involves movement that changes the location of an object. However, the child's goal in "getting" appeared to be more the act of obtaining than a change in location of the object, and utterances such as "get it" and "get cookie" were classified as action-on-affected-object. The definitions used for categorizing the relations between words in multiword utterances can be found in Bloom, Lightbown, \& Hood (1975).

The relative occurrence of spontaneous and imitative utterances in each of the categories will be reported: (1) for categories in which there were at least five utterance types at a particular time and (2) for those times in which the proportion of different imitative utterances exceeded .15 of the total number of different utterances: Peter, Times I- VII; Kathryn, Time I; Jane, Times I and II; and Eric, Times I-IV. The criterion of an overall proportion of imitation of .15 was used because below that level there were too few different imitative utterances to allow for a meaningful comparison between imitative and spontaneous speech. Utterance types that had both spontaneous and imitative tokens were not included in this analysis; they represented less than .10 of all the syntactic utterance types from all the children, and they did not include any different categories.

The evidence of the interaction between imitative and spontaneous speech for semantic-syntactic learning will be presented as frequency data: the number of imitative and spontaneous multiword utterance types within each category of semantic-syntactic relationship. In all the samples, there were several noncontrastive categories in which there was either little difference in the form of imitative and spontaneous speech, or few imitations. For other categories, spontaneous and imitative multiword utterances could be compared with respect to the development of different linguistic forms (subcategories) within each semantic-syntactic category. For example, in Peter's speech, in the category action-on-affected-object, the subcategories were pronominal and nominal lexicalization of affected-object. In addition to presenting the observed occurrence of different utterances, the expected occurrences within subcategories will be presented. Expected frequencies were determined from the overall proportion of different syntactic utterances imitated at each time (see Table 2). The information presented here consists of the observed and expected occurrence of utterance types that were imitative or spontaneous, within categories and across time.

Peter I-VII. There were no productive categories (with productivity defined as five or more different utterances within a category) in Peter's speech samples at Times I and II. Several semantic-syntactic categories reached the criterion of productivity at Time III. As will be seen, the relative occurrence of imitative and spontaneous utterances at Time VI, when MLU was 1.75, forced the decision to consider the next sample, Time VII, when MLU was 2.39 and beyond the original limits of the study.

Existence. In Peter's speech, reference to existence was made by utterances with a primitive form of $a$ or the or a demonstrative pronoun (the subcategories /o/ (schwa) and Dem in Figure 2) and a noun. There were few utterances with a demonstrative pronoun at Times III, IV, and V, and those that did occur were largely imitative. At Time $\mathrm{V}$ there were 1 spontaneous and 4 imitative utterances with a demonstrative. At Time VI there were 10 spontaneous utterances with a demonstrative, but there were 19 utterances that were imitative, which greatly exceeded the expected frequency of imitative utterances, given the overall proportion of syntactic imitation at Time VI. That is, inasmuch as $38 \%$ of all Peter's different syntactic utterances at Time VI were imitative, the observed ratio of imitative to spontaneous occurrence was inversely related to the expected ratio in the 
Demonstrative subcategory. However, in the next sample at Time VII, the situation was reversed. Only 4 utterances with a demonstrative were imitative, while 29 utterances occurred spontaneously. The observed imitative to spontaneous ratio was in the expected direction, with the observed occurrence of imitation below expected occurrence.

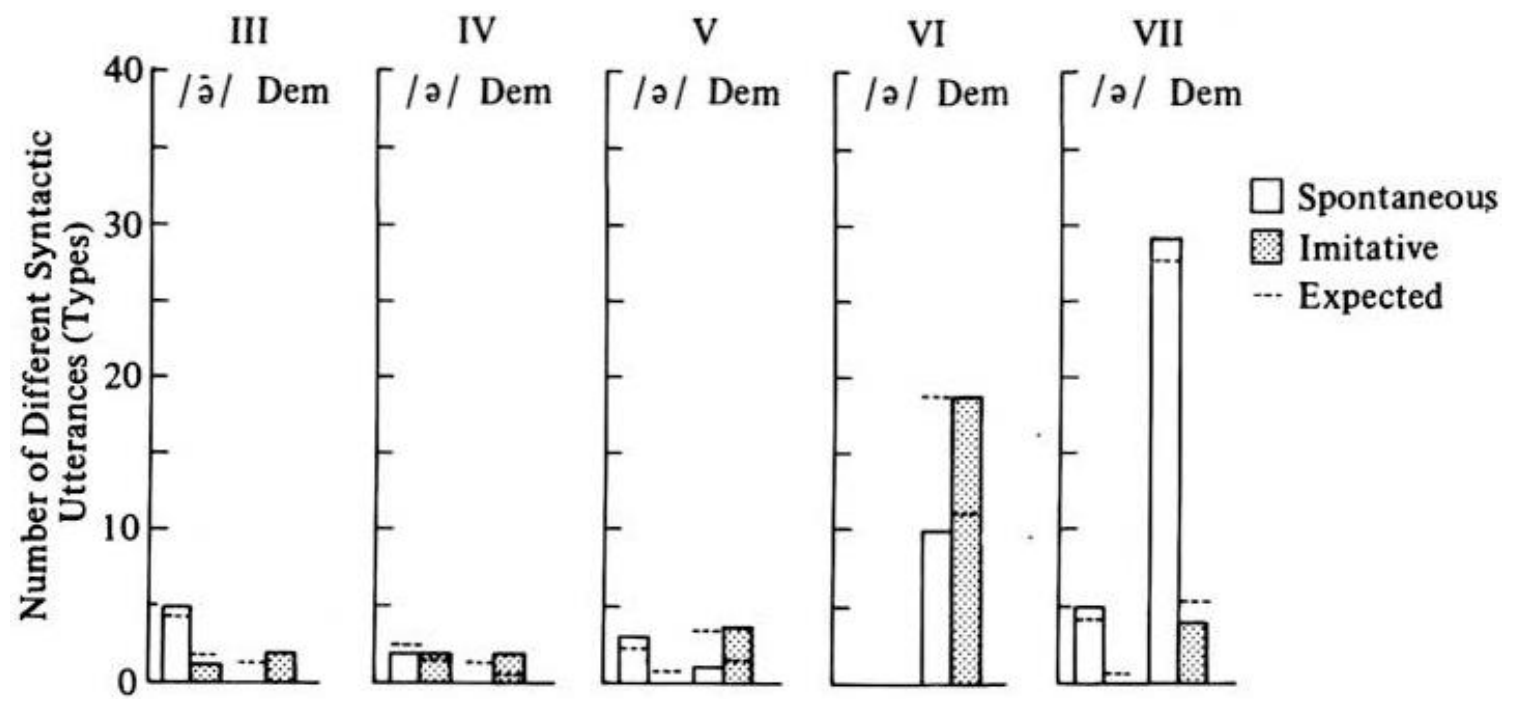

Figure 2. Peter, Times III-VII. Spontaneous and Imitative Expressions of Existence

Thus, there was a subcategory shift in the linguistic form of utterances specifying Existence, from imitative to spontaneous occurrence of demonstrative pronouns, between Times VI and. The imitation data at Time VI provided evidence that he was in the process of learning demonstratives while the relation between imitative and spontaneous occurrence at Time VII indicated that he had learned them. Utterances with /ə/ occurred less often and except at Time IV they were rarely imitative.

Action-on-Affected-Object. The most dramatic interaction between imitative and spontaneous speech was in the category Action-on-Affected-Object in which the subcategories were Pronominal (Pro) and Nominal (Nom) lexicalization of affected-object. Both a category shift and a subcategory shift from imitative to spontaneous use occurred. As can be seen in Figure 3, more of the 17 different utterances in the category at Time III were imitative than spontaneous, and the observed ratio of imitative to spontaneous occurrence was inversely related to the expected imitative to spontaneous ratio. The category shift occurred between Time III, when Peter was learning the category, and Time IV, when he had learned the category Action-on-Affected-Object, since the observed and expected ratios of imitative to spontaneous occurrence were in the same direction. Subsequently, at Time V it might be said that Peter consolidated his gains and used the pronoun it overwhelmingly to represent affectedobject in the category Action-on-Affected-Object.

The pronominal to nominal subcategory shift occurred between Times VI and VII. The observed and expected ratios of imitative to spontaneous occurrence with the pronoun it were in the same direction after Time III. However, with nominal objects, the observed and expected ratios changed from an inverse to direct relationship at Time VII, and further, the number of different utterances with a noun-object was greater than the number of utterances with it at Time VII. Thus, Peter learned the category between Times III and IV, and learned to use noun-objects in affected-object relation to action verbs between Times VI and VII. The fact that there were more spontaneous than imitative noun-objects at Time IV could not be explained; it was the only instance in all the samples from all the children of a spontaneous to imitative subcategory progression. 


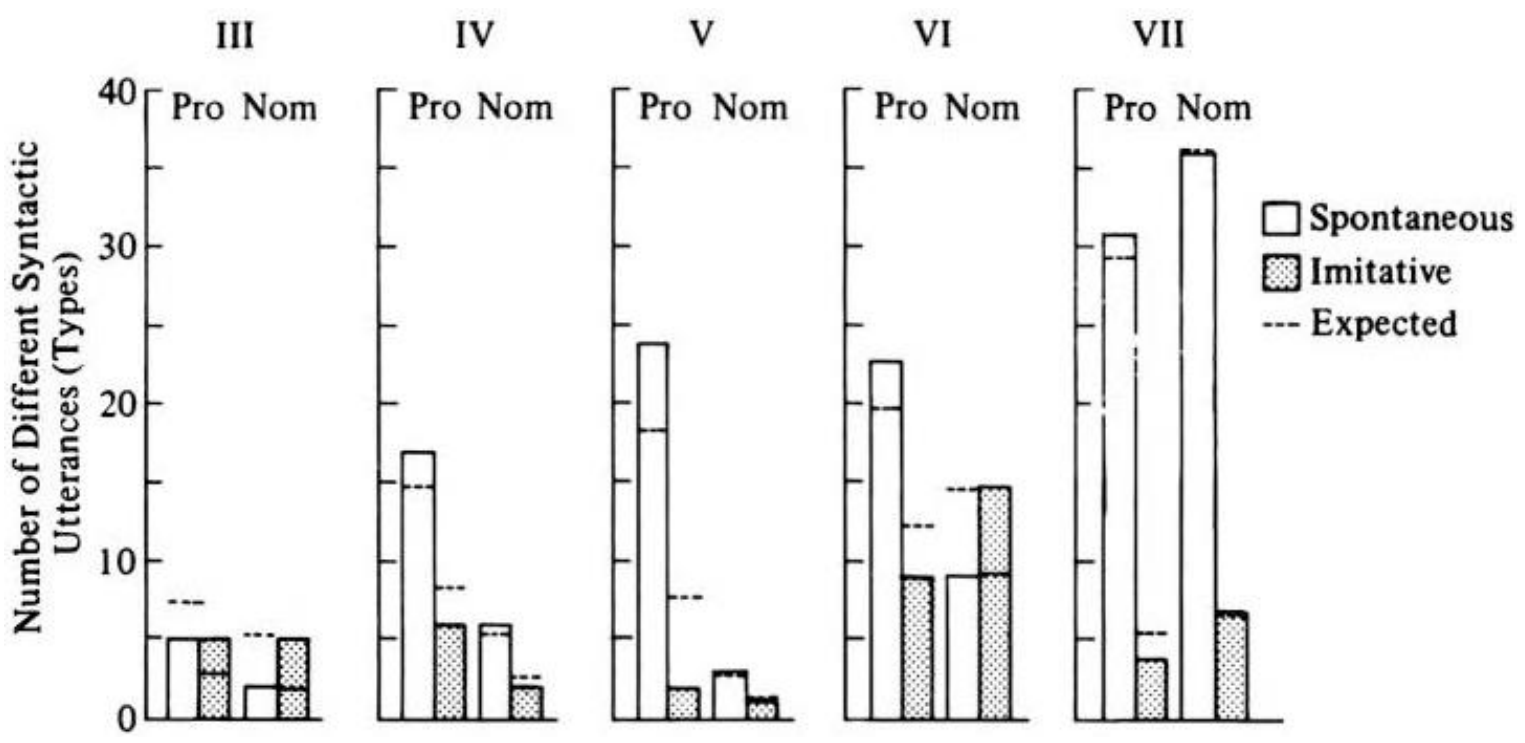

Figure 3. Peter, Times III-VII. Spontaneous and Imitative Expressions of Action-on-Affected Object

Attribution. In the category Attribution (Figure 4), the subcategories were "two," in reference to two objects or a second object (a few utterances with two, with no evidence of duality in the context, were not included in Figure 4), and other attributive forms such as big, nice, dirty, and funny. Peter was learning attributive reference from Time III through Time V, and the evidence of a category shift at Time VI was that Peter had learned to use the word two to talk about exactly two objects or a second object, and he rarely imitated such utterances. However, the inverse relation between observed and expected occurrence of imitative and spontaneous utterances with other attributive forms continued from Time III through Time VI. Further, even though the observed and expected ratios of imitative to spontaneous occurrences with other attributives were in the same direction at Time VII, the observed frequency of imitative utterance types was still considerably greater than the expected frequency. At Time VII, Peter had learned the single attributive form two and no longer imitated that form, but he was still in the process of learning to use a class of other forms for attributive reference at Time VII.

Locative Relations. An example of the interaction between spontaneous and imitative speech in the locative categories is presented in Figure 5. Whereas action verbs had been productive since Time III, locative-action verbs did not occur in multiword utterances until Time V. Utterances in the category Place-of-Locative Action (with verb expressed), for example, "put there" or "put car" were always more frequent than utterances in the category Object-of-Locative Action (with verb expressed), for example, "put pretzel" or "put it." Thus, reference to affected-object was more likely to occur when Peter used an action verb than when he used a locative-action verb which could entail two complements: both affected-object and place. 


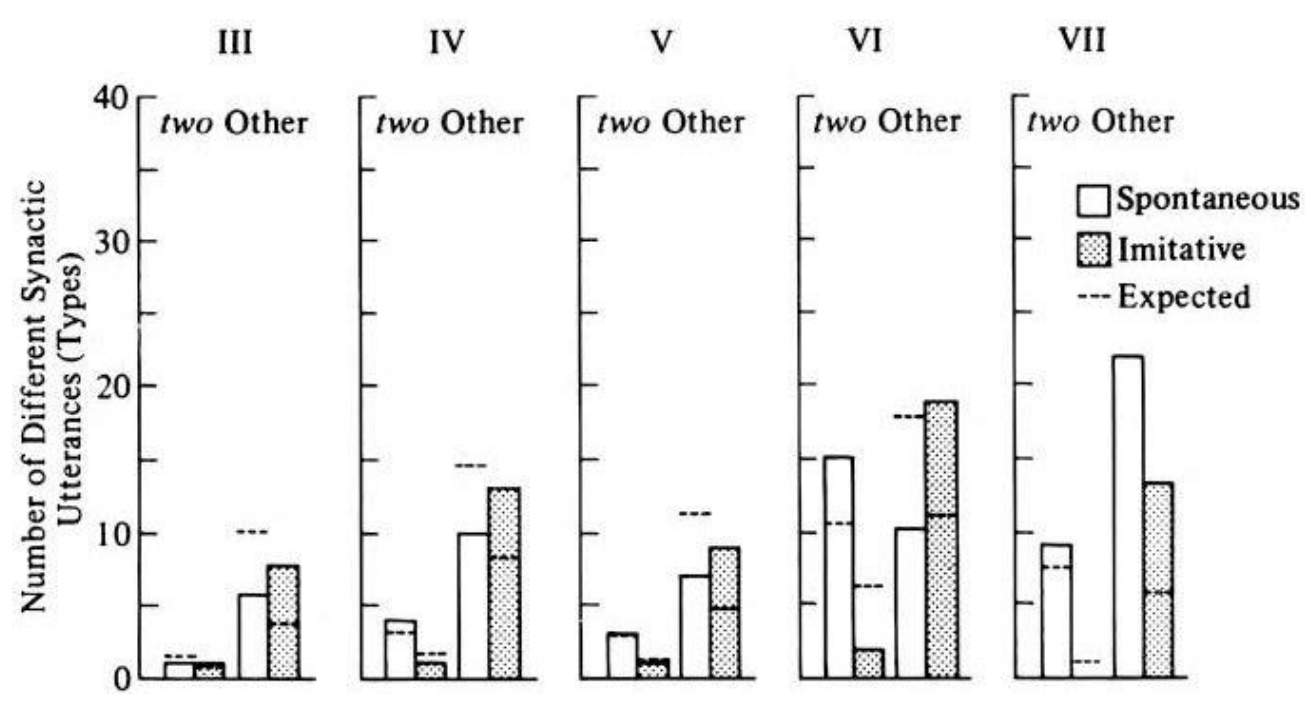

Figure 4. Peter, Times III-VII. Spontaneous and Imitative Expressions of Attribution

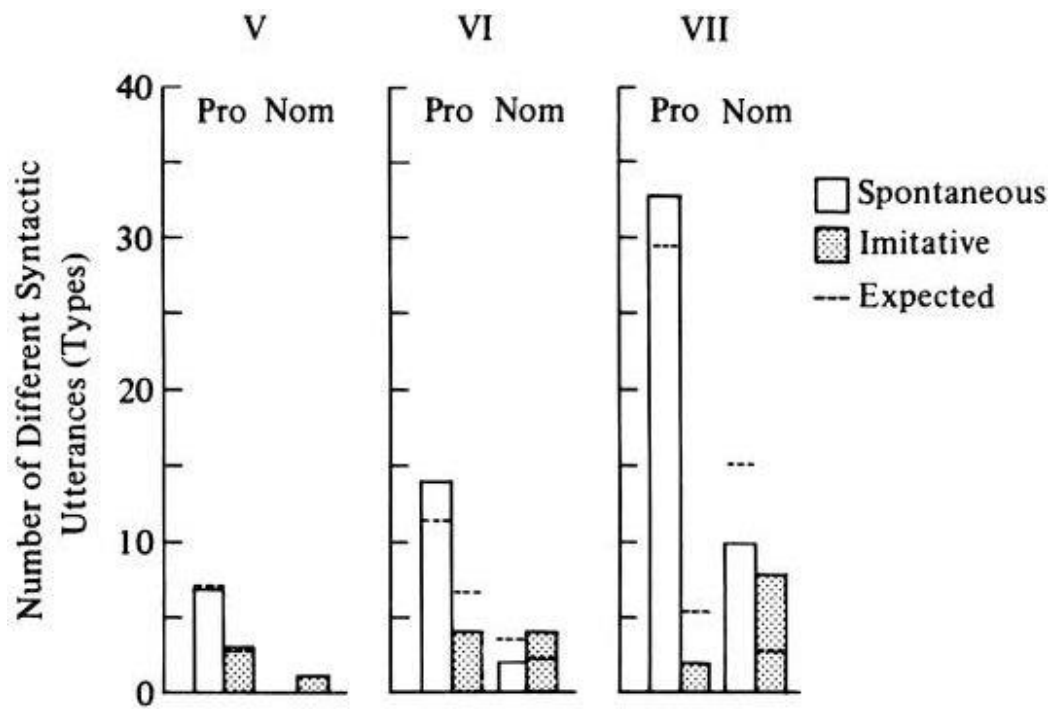

Figure 5. Peter, Times V-VII. Place-of-locative action with a verb expressed.

New Categories at Time VI. The proportion of syntactic imitation in Peter's speech decreased markedly between Times VI and VII, (from .38 to .16). It might be argued that the subcategory shifts that have been described did not have to do with semantic-syntactic learning as much as they were a function of the decrease in imitation in general between Times VI and VII. However, as seen in Figures 4 and 5, the observed frequency of imitation continued to be greater than the expected frequency of imitation at Time VII. The interaction between imitative and spontaneous speech continued with new categories that first appeared at Time VI, as can be seen in the examples in Figures 6 and 7. 


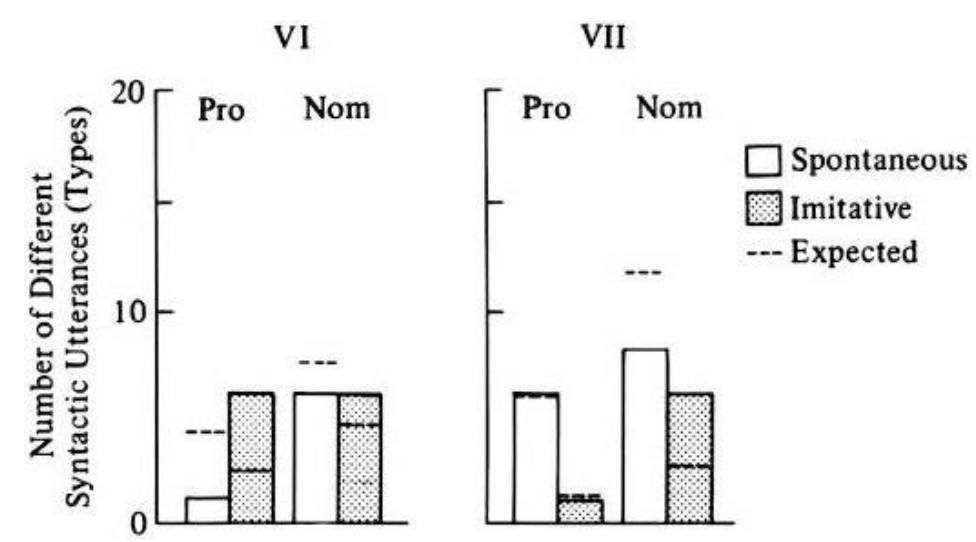

Figure 6. Peter, Times VI and VII. State-and-causative-object.

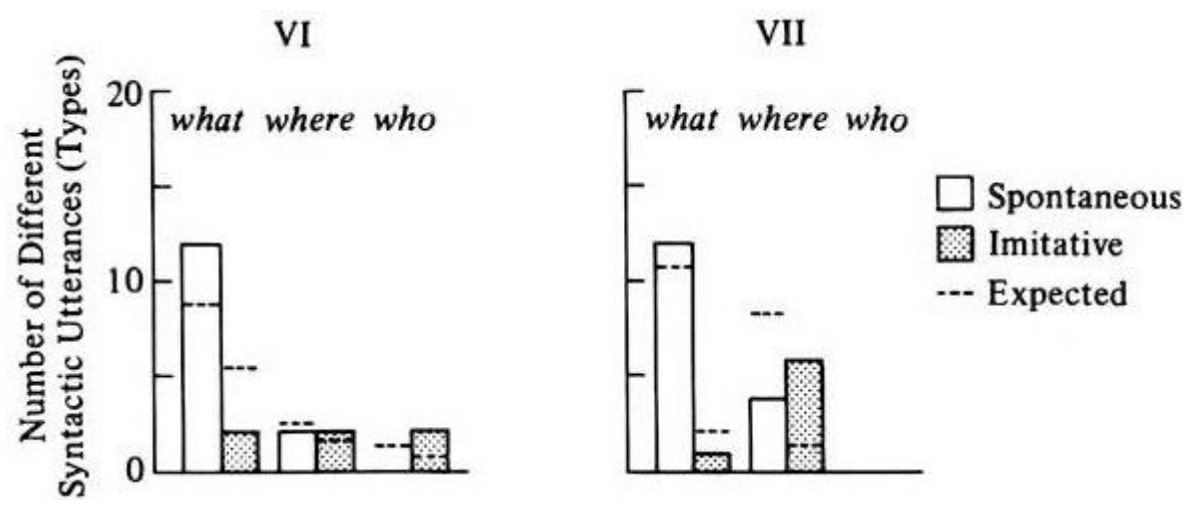

Figure 7. Peter, Times VI and VII. Wh-questions.

The data from Peter demonstrated the interaction between imitative and spontaneous speech most explicitly: Imitation occurred within semantic categories and with forms that were just emerging. Peter did not imitate what he knew best, and he did not imitate what he knew nothing about. Whenever imitation exceeded expectation, there were always spontaneous utterances within the same category or subcategory as well. Peter imitated utterances in just those categories and subcategories which were to become fully productive at a subsequent time but which were currently beyond his productive capacity. To that extent, imitation provided evidence of grammatical learning.

Peter imitated more than the other children. Furthermore, the Peter data were collected at three-week intervals, so that the developmental changes in his speech might have been missed if data collection had been more widely spaced. However, the same interaction between imitative and spontaneous utterance types within certain categories was observed in Kathryn I and Jane I and II.

Kathryn I. A comparison of spontaneous and imitative utterances in Kathryn's speech is presented in Table $5 .{ }^{9}$ As with Peter, the dominant semantic-syntactic category involved action. However, whereas in Peter's speech pronominal reference was always far more frequent than nominal reference, and Peter progressed from pronominal to nominal reference from Time III to Time VII, pronouns occurred rarely in Kathryn's speech and were imitated more often than spontaneous.

9 Data from 5 of the original 7.5 hours of interaction with Kathryn at Time I were processed for the following analysis, and for this reason the numbers of utterances in particular categories do not correspond to the account in Bloom (1970). 
Table 5. Kathryn, Time I, Contrastive Semantic-Syntactic Categories

\begin{tabular}{|c|c|c|c|c|c|c|c|c|}
\hline \multirow{5}{*}{$\begin{array}{l}\text { Semantic- } \\
\text { Syntactic } \\
\text { Category }\end{array}$} & \multicolumn{8}{|c|}{$\begin{array}{l}\text { Observed and Expected Occurrence of Spontaneous and Imitative } \\
\text { Utterance Types }\end{array}$} \\
\hline & \multicolumn{8}{|c|}{ Subcategories } \\
\hline & \multicolumn{4}{|c|}{ Pronominal } & \multicolumn{3}{|c|}{ Nominal } & \\
\hline & \multicolumn{2}{|c|}{ Spont } & \multicolumn{2}{|l|}{ Imit } & \multicolumn{2}{|c|}{ Spont } & \multicolumn{2}{|l|}{ Imit } \\
\hline & Observ & Expect & Observ & Expect & Observ & Expect & Observ & Expect \\
\hline Agent-Action & 1 & 2 & 2 & 1 & 12 & 8.6 & 1 & 4.4 \\
\hline Action-on-Object & 1 & 2.6 & 3 & 1.4 & 21 & 19.1 & 8 & 9.9 \\
\hline Place & - & 2 & 3 & 1 & 1 & $3 \cdot 3$ & 4 & 1.7 \\
\hline Possession & 1 & 2.6 & 3 & 1.4 & 8 & 9.2 & 6 & 4.8 \\
\hline Attribution & 1 & 2 & 2 & 1 & 28 & 23.8 & 8 & 12.2 \\
\hline Recurrence $^{\mathrm{a}}$ & more & & & & another & & & \\
\hline \multirow{3}{*}{ Notice } & 13 & 8.6 & - & $4 \cdot 4$ & 2 & 4.6 & 5 & 2.4 \\
\hline & $\mathrm{Hi}$ & & & & Verb & & & \\
\hline & 4 & 2.6 & - & 1.4 & 3 & 5.9 & 6 & 3.1 \\
\hline
\end{tabular}

Jane I and II. Spontaneous and imitative utterances in Jane's speech are compared in Figure 8. The data collected from Jane were the least satisfying for several reasons. First, her family moved out of town after the second session, so that it was not possible to follow development in those categories that were predominantly or only imitative at Time II. Second, even though 6 weeks elapsed between Times I and II, there was virtually no change in mean length of utterance and change in only three semantic-syntactic categories: the subcategory shift with Action-on-Affected-Object, and the appearance of two new categories at Time II, Locative-State and Attribution. Finally, there was a relatively large number of nonproductive categories-more than for Peter, Kathryn, or Ericwhich gave the impression that Jane had spread herself thin, trying to learn many things at once. However, as with Peter and Kathryn (at Time I), it was possible to conclude that Jane was indeed using imitation in processing information about the semantic-syntactic relations between words as she learned grammar. 


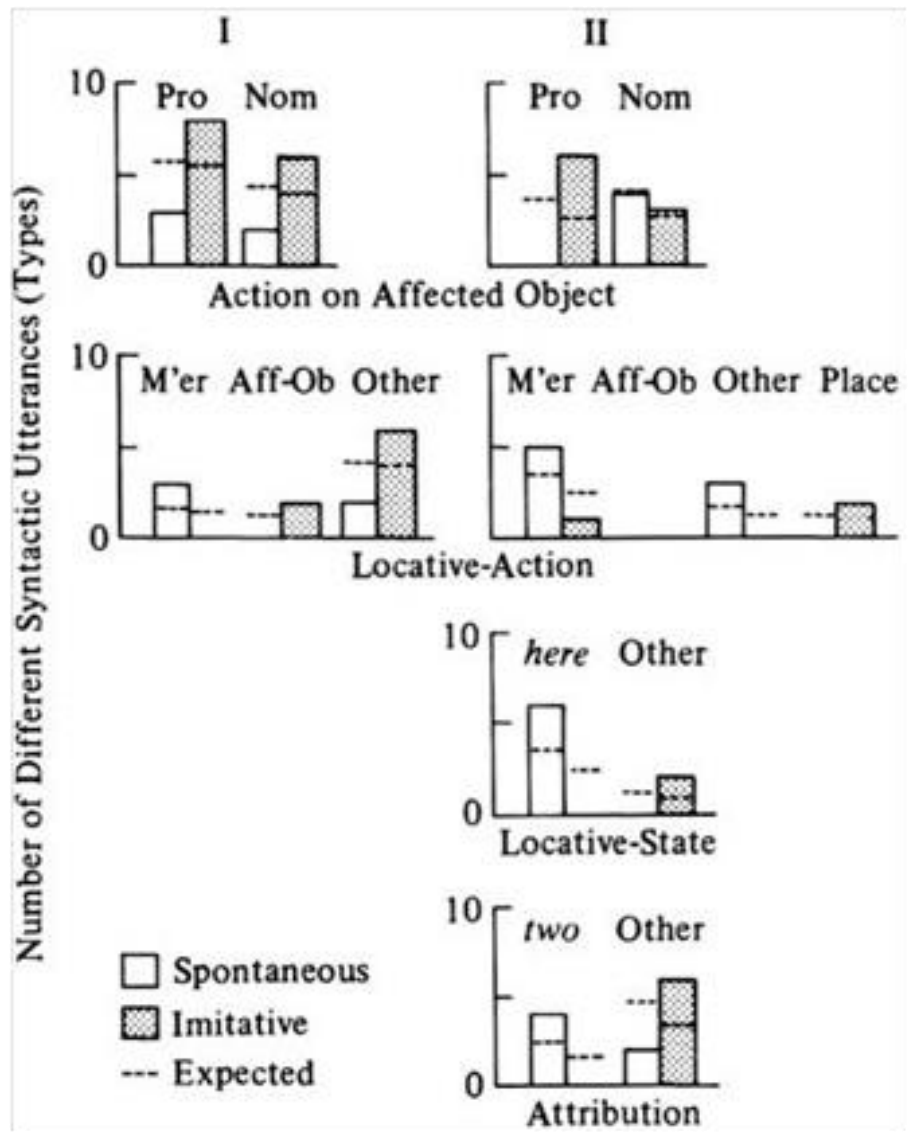

Figure 8. Jane, Times 1 and II. Semantic-syntactic categories.

Eric I-IV. The data from Eric told a different story about the relationship between imitative and spontaneous utterances: None of the semantic-syntactic categories was contrastive. As can be seen in Figures 9 and 10, imitative multiword utterances were relatively infrequent. The observed and expected imitation in each category was virtually identical, in marked contrast to the differences between observed and expected imitation in the speech of the other children. This observed-expected convergence in Eric's syntactic speech was evidence that his imitative behavior was not motivated by his learning the semantic-syntactic structure of multiword utterances.

As already reported, Eric was apparently using imitation in the process of learning individual lexical items. It appears that Eric's imitation of multiword utterances was also lexically motivated. Individual words that occurred in imitative multiword utterances did not also occur in spontaneous multiword utterances. However, the words in imitative multiword utterances occurred both spontaneously and imitatively as single-word utterances in the same sample. This parallels the finding that for the children whose imitation was evidence of semantic-syntactic learning, utterance types were imitative in semantic-syntactic categories only where there were spontaneous utterance types as well.

The semantic-syntactic categorization of utterances revealed that for Eric, as with the other children, imitation was never random, given the two results: (1) a difference between lexical items that were spontaneous and imitative in syntactic contexts and (2) the overall proportion of imitation in his speech predicted the proportion of imitation within each semantic-syntactic category. Thus, Eric imitated new lexical items he heard in speech that encoded the same kind of knowledge as his own multiword utterances. His knowledge of semantic- syntactic relations appeared to structure his processing of new lexical items. 

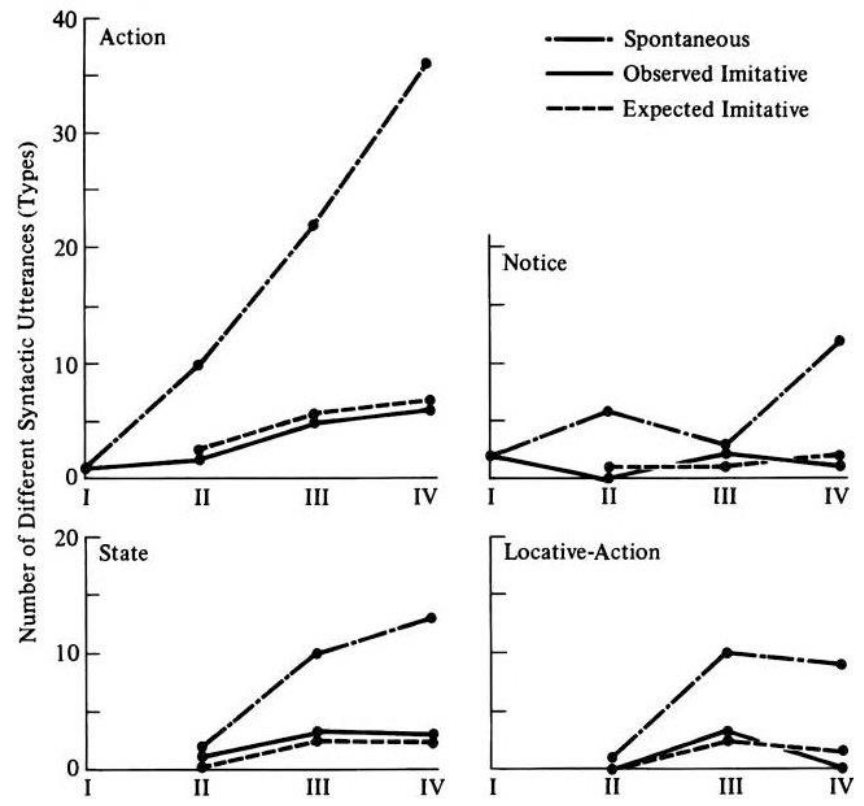

Figure 9. Eric Times I-IV. Relative frequency of utterances with different verbs.
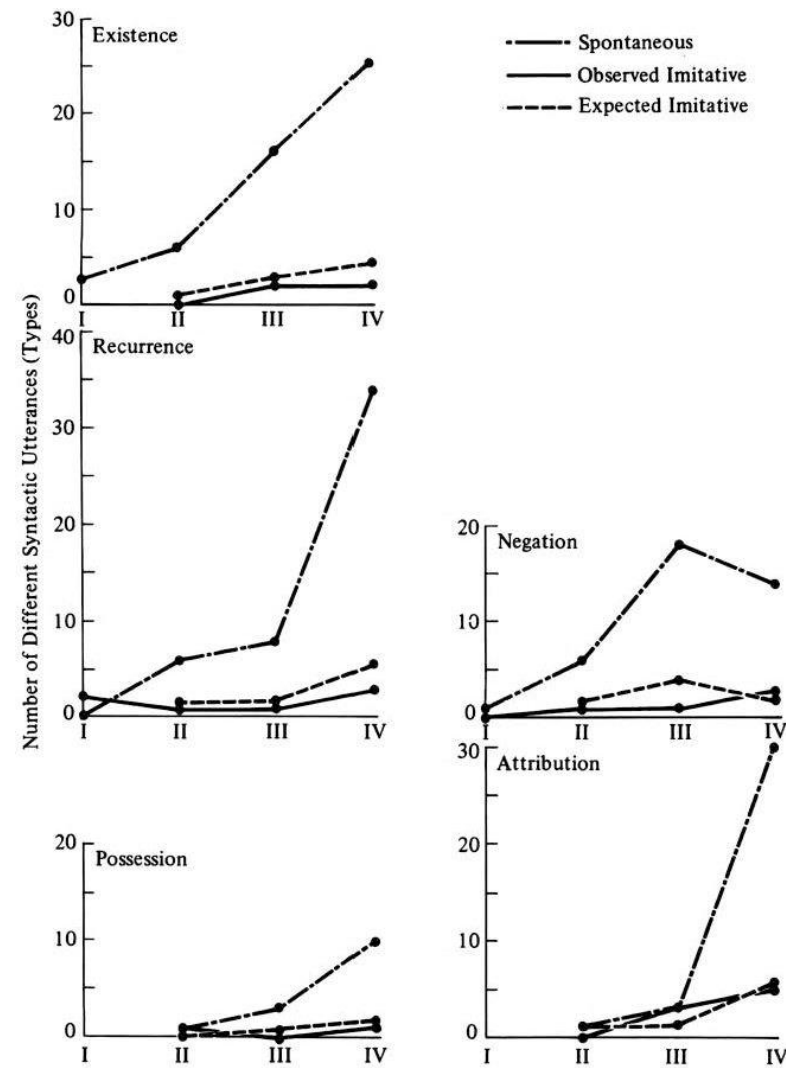

Figure 10. Eric Times I-IV. Relative frequency of utterances in semantic-syntactic categories..

The difference between Peter and Eric in progression from imitative to spontaneous use of words reported earlier (the progression occurred in single-word utterances for Peter and in multiword utterances for Eric) corresponded 
to the differences observed between them in the semantic-syntactic analysis. Peter apparently imitated words that he already knew in semantic-syntactic relations that he was in the process of learning. Eric, however, imitated words he did not yet know that occurred in the semantic-syntactic relations that he already was able to use spontaneously.

\section{Imitation and Utterance Length.}

When mean length of utterance (morphemes) was computed separately for spontaneous and imitative utterances, two different trends appeared for imitating and nonimitating children. For those samples where the overall proportion of imitation was less than .15, MLU was consistently higher for spontaneous utterances than for imitative utterances. However, in those language samples where the overall proportion of imitation was greater than .15 , the MLU of imitative utterances usually equaled or exceeded the MLU of the spontaneous utterances. The claim that imitation had an important function in the language development of the children who imitated does not require that imitative utterances be longer than spontaneous ones-only that they be different and that the differences be related to developmental change. The lexical and semantic-syntactic analyses made it clear that these differences did exist. The longer MLU of the imitative speech simply represented a superficial index of such differences.

\section{Summary.}

In the syntactic speech of Kathryn at Time I, Jane, and Peter, certain categories and subcategories that were productive in spontaneous speech were imitated rarely, if at all. However, it was almost always the case that when observed imitation exceeded expected imitation within a category or subcategory, there were spontaneous utterance types as well-evidence that the children already knew something about what they were imitating. This result does not conflict with the earlier finding that different lexical items were only imitative or only spontaneous; both kinds of utterance types (lexical items and multiword) were either imitative or spontaneous, as indicated by the small number of Spont + Imit in Table 2. However, the lexical analysis was based on token frequencies, whereas for multiword utterances the important analysis was the relative spontaneous and imitative occurrences of utterances types within semantic-syntactic categories. The categories included both spontaneous and imitative utterance types, but each multiword utterance type was either imitative or spontaneous.

Finally, the developmental interaction between imitative and spontaneous speech moved in the same direction -from imitative to spontaneous occurrence-for lexical items (in the speech of Peter and Eric) and grammatical structure (in the speech of Peter, Jane, and Kathryn). Once lexical items and semantic-syntactic categories and subcategories were observed to be predominantly spontaneous, they were never predominantly imitative in subsequent samples. Imitation appeared to function for learning the semantic-syntactic relations in multiword utterances for Peter, Jane, and Kathryn. However, in Eric's speech, the semantic-syntactic relations between words were not different in imitative and spontaneous utterances, and the motivation for imitation in Eric's speech was lexical. Whether lexical or grammatical, imitation in the children's speech was developmentally progressive.

\section{DISCUSSION}

Before discussing the results of this study as evidence of processing information for language development, the results will be compared with two other studies that also examined and compared children's imitative and spontaneous utterances: Ervin-Tripp (1964) and Kemp and Dale (1973), and with other discussion of imitation in the literature. ${ }^{10}$

In the study by Ervin-Tripp, rules of grammar were proposed for the spontaneous utterances in the speech of five children who ranged in age from 22 to 34 months, and then the children's imitative utterances were examined to determine the extent to which they were consistent with the rules of grammar. In the speech of four of the children, both imitative and spontaneous utterances could be accounted for by the same rules. For the fifth child,

\footnotetext{
${ }^{10}$ Some of the issues in the present paper were also discussed by Miyamoto (1973). Ryan (1973) independently presented data that complement the data presented here, with strikingly similar interpretations and conclusions.
} 
imitative utterances were shorter and less complex than spontaneous utterances..$^{11}$ Ervin-Tripp concluded that imitation was not "grammatically progressive" for the five children. According to the examples of grammars, the rules on which the analysis was based were rules of word order in which three or more optional classes of words were ordered relative to a final required class. The optional classes included articles, demonstrative pronouns, attributives, certain verbs, and such words as more and no. In some rules the final optional class was virtually identical to the required class, which included noun forms and certain other attributives (for example, color names). ${ }^{12}$ This result was consistent with the report by Brown and Fraser (1963) that both imitative and spontaneous child speech preserved the word order of the model language.

In the present study, rules of word order would not have differentiated between imitative and spontaneous utterances either. Demonstratives, articles, verbs, attributives, and such forms as more and no preceded object nouns in both kinds of speech. Thus, it was not so much the case that the results reported here were inconsistent with Ervin-Tripp's conclusions. Rather, the analysis she reported was simply not sensitive enough to detect the differences that might have existed between the two kinds of utterances in her data.

Kemp and Dale (1973) embedded model sentences in the speech that they addressed to 30 children between the ages of 22 and 36 months during play. They interpreted two results as opposing: (1) On the one hand, since certain grammatical features which occurred in free speech were never imitated, they concluded that imitative speech was even less advanced than spontaneous speech; (2) on the other hand, since other grammatical features occurred in imitative utterances but not in free speech, then imitative speech could be grammatically progressive. Similar results in the present study were interpreted as complementary aspects of the nature of imitation in language development.

\section{To Imitate or Not to Imitate}

The variation among the six children in this study with respect to if they imitated (their relative tendency to imitate), and when they imitated (the lexical and grammatical conditions that accompanied imitation), may explain some of the confusion in the literature of the last century about the importance of imitation for language development. The more important theoretical issues have evolved about the central question of why some children imitate: how imitation may function as a process in language development.

Certain speculations that might explain why some children imitate in the first place cannot be resolved by the data or the results of this study. Such factors as parent-child interaction, personality, or intelligence might well have been important as predisposing factors that determined whether a child was or was not an imitator in the first place. As such, they would appear to be empirical issues that could be tested elsewhere. However, such factors are essentially passive influences on behavior since an individual's intelligence, personality, and parents are not self-determined. Thus, children may not be able to control whether or not they are imitators in the first place. But if they do imitate, it appears that when they imitate and why are self-determined, to the extent that both are based on what the child already knows and is in the process of learning.

\section{Imitation as an Active Process}

If certain model utterances had not been available for a child to imitate then, obviously, they could not have appeared among the imitative utterances, and the fact that they did not occur would have been determined by the environment and not by the child. However, Peter had ample opportunity to imitate both pronominal and nominal reference to affected-objects at Time IV, as revealed by the following analysis. All the adult utterances to Peter that (1) immediately preceded an utterance by Peter and (2) represented Notice or Action-on-AffectedObject were compared with Peter's subsequent utterances, for the first 2 hours (almost one-half) of the sample at Time IV. There were 45 adult utterances that met the criteria, and 20 of these included pronouns as affectedobject ( 2 with one and 18 with $i$ ). Peter imitated only one of these. In all other instances, he either said something related to the utterance or repeated a previous utterance. Yet in his spontaneous speech, pronominal reference

11If children imitate what they do not quite know, then imitations might well be more fragmented and less 'complete' than other speech, as was the case with a few of the samples from the imitating children in the present study.

${ }^{12}$ Subsequently, Ervin-Tripp (personal communication) reported that other grammars not discussed in her original report were more complex. 
occurred far more often than nominal reference. The fact that Peter did not imitate utterances with pronominal reference even though they were present in the input was evidence that Peter determined what he did and did not imitate.

The fact that imitation is selective has been reported frequently, if not actually demonstrated, by Guillaume (1926/1968), Valentine (1930), Jakobson (1941/1968), Aronfreed (1969), and others. However, different factors have been thought to underlie the choice of what is imitated. On the one hand, if each time a child imitates, the relation between a linguistic signal and its referent in a speech event is affirmed, then an intrinsic reinforcement could serve to maintain imitation behavior. In this case, the reward for imitation is learning-a conclusion that would be supported by the data presented here. On the other hand, it is frequently presumed that children repeat the speech they hear because such behavior is rewarded by the environment. Several theories to explain language development have depended on such a chain of events whereby the child hears a stimulus, repeats it, and is reinforced by an adult in the situation who may smile, repeat it again, supply a referent, and so on (Allport, 1924; Jenkins \& Palermo, 1964; Mowrer, 1960; Staats, 1971). While children may well enjoy whatever attention is given to imitating behavior, such pleasure and attention alone would not explain the systematic relationship between imitative and spontaneous utterances in the children's speech that was observed in this study.

The idea that a child's imitation is determined or shaped by reinforcement from the environment is another view of the child as essentially passive with respect to the forces that contribute to and maintain behavior. Similarly, the view of language development that depends upon an independent cognitive structure for organizing linguistic input, such as the "language acquisition device" proposed by Chomsky (1965) and McNeill (1970), places the child in another kind of passive role. Both the behaviorist and the nativist positions result in the conclusion that the child is simply the victim of fate and circumstance in learning to talk. But whatever the nature of children's linguistic knowledge may be at any time, they add to and change that knowledge in relation to experience. The results of this study have emphasized the active interaction of the child in language development: The children appeared to imitate as they processed linguistic and nonlinguistic input from the environment for information about language.

Piaget (1951/1962) distinguished between early sensorimotor imitation in the first two years and later "representative" imitation that begins some time toward the end of the second year. During the sensorimotor period, according to Piaget, imitation is unconscious and comes about through confusion between the movements of others and movements of the self. Because children are unable to differentiate between internal and external states, they cannot distinguish their own actions and movements from those that they see. Sensorimotor imitations are provoked from "direct perceptions." An important change occurs at the end of the second year and continues into the early school years (to about age 7), as the reproduction of a model comes to be preceded by an "imaged representation" of it. It is this reproduction of an image of the model that is characterized by Piaget as "representative imitation" that is "deferred." Although the model is not perceptually present, the child necessarily has an image of the model in mind before reproducing it. ${ }^{13}$

The imitation behavior in the present study would qualify as sensorimotor imitation as described by Piaget to the extent that the model utterances were perceptually present. Indeed, the operating definition of imitation depended upon "direct perception," even though perception and production were sequential (as was the case with the imitative behavior described by Piaget). However, the important result of this study of such perceptual imitation was that the children's behavior was discriminating in that they differentiated among stimuli in a highly systematic way. The imitating children discriminated, first, between their own linguistic behavior and the behavior of others and, second, among the different linguistic behaviors of others. They imitated only words and structures in the speech they heard which they appeared to be in the process of learning. They tended not to imitate words and structures that they themselves either used spontaneously and so presumably knew or did not use spontaneously at all and so presumably did not know. Imitative behavior was not merely acoustic or an automatic echoing of random linguistic events.

13Piaget discussed linguistic imitation only in the context of imitation in general as it functions in the development of symbolic thought. 
In conclusion, when and why the imitating child would imitate depended upon what was already known about one or another aspect of language. The important facts were that the children imitated neither linguistic signals that were already well known to them nor structures that were completely absent from their own spontaneous speech. Peter imitated relatively new semantic-syntactic structures that included words that he used spontaneously elsewhere; Eric imitated new words only when they occurred in the same semantic-syntactic structures as were represented in his spontaneous speech. Similarly, in the study by Shipley, Smith, and Gleitman (1969), the novel (nonsense) words that seemed to precipitate imitation were embedded in standard sentence frames and in familiar contexts. The conclusion by Fraser, Bellugi, and Brown (1963) that imitation precedes comprehension and production in development was not supported. Rather, the results confirmed the observations of Preyer (1882/1971), Guillaume (1926/1968), Valentine (1930), and others that children imitate only what they already understand to some extent. Piaget (1937/1954) observed that imitation is always a continuation of understanding.

One might explain imitation as a form of encoding that continues the processing of information necessary for the representation of linguistic schemas (both semantic and syntactic) in memory. In the imitation context, the child has the perceptual support of a model utterance relative to events which, while recognized, are only partially mapped onto linguistic schemas. Imitating the model utterance provides experience in encoding the relevant aspects of the situation to which the utterance refers, consolidating the mapping or coding relation between form and content. Although the imitation behavior observed in this study provided evidence of such active processing of linguistic and nonlinguistic information for learning the relation between the form of speech and the nonlinguistic states of affairs to which it refers, it was not clear that the imitation behavior was necessary for such information processing. Further, it was apparent that some processing of the same kind of information input is possible without such supported encoding, certainly for the nonimitating children and perhaps for the imitating children as well.

\section{REFERENCES}

Allport, F. (1924). Social psychology. Boston: Houghton Mifflin.

Aronfreed, J. (1969). The problem of imitation. In L. Lipsitt \& H. Reese (Eds.), Advances in child development (vol. 4, pp. 210-319). New York: Academic Press.

Bellugi, U., \& Brown, R. (Eds.) (1964). The acquisition of language. Monographs of the Society for Research in Child Development, 29 (serial no. 92).

Bloch, O. (1921). Les premiers stades du language de l'enfant. Journal de Psychologie, 18, 693-712.

Bloom, L. (1968). Language development: Form and function in emerging grammars. Ph.D. diss., Columbia University.

Bloom, L. (1970). Language development: Form and function in emerging grammars. Cambridge, MA: MIT Press.

Bloom, L. (1973). One word at a time: The use of single-word utterances before syntax. The Hague: Mouton.

Bloom, L. (1992). Racism in developmental research. President's Message, Division 7 Newsletter. Washington, DC: American Psychological Association, Fall-Winter.

Bloom, L., \& Lahey, M. (1978). Language development and language disorders. New York: Wiley.

Bloom, L., Lightbown, P., \& Hood, L. (1975). Structure and variation in child language. Monographs of the Society for Research in Child Development, 40 (serial no. 160).

Brown, R., \& Fraser, C. (1963). The acquisition of syntax. In C. Cofer \& **?Musgrave (Eds.), Verbal behavior and verbal learning: Problems and processes (pp. 158-97). New York: McGraw-Hill.

Chomsky, N. (1957). Syntactic structures. The Hague: Mouton.

Chomsky, N. (1959). Review of B. F. Skinner, Verbal behavior. Language, 35, 26-58. 
Chomsky, N. (1965). Aspects of the theory of syntax. Cambridge, MA: MIT Press.

Dixon, T., \& Horton, D. (1968). Verbal behavior and general behavior theory. Englewood Cliffs, NJ: PrenticeHall.

Ervin-Tripp, S. (1964). Imitation and structural change in children's language. In E. Lenneberg (Ed.), New directions in the study of language (pp. 163-89). Cambridge MA: MIT Press.

Fraser, C., Bellugi, U., \& Brown, R. (1963). Control of grammar in imitation, comprehension and production. Journal of Verbal Learning and Verbal Behavior, 2, 121-35.

Guillaume, P. (1926/1968). Imitation in children. Chicago: University of Chicago Press.

Jakobson, R. (1941/1968 translation). Child language, aphasia and phonological universals. The Hague: Mouton.

Jenkins, J., \& Palermo, D. (1964). Mediation processes and the acquisition of linguistic structure. In U. Bellugi \& R. Brown (Eds.), The acquisition of language. Monographs of the Society for Research in Child Development, 29 (serial no. 92).

Jespersen, O. (1922). Language: Its nature, development, and origin. London: Allen \& Unwin.

Kemp, J., \& Dale, P. (1973). Spontaneous imitation and free speech: A developmental comparison. Paper presented to the biennial meeting of the Society for Research in Child Development, Philadelphia.

Kirkpatrick, E. (1909). Genetic psychology. New York: Macmillan.

Leopold, W. (1939-1949). Speech development of a bilingual child (vol. 3). Evanston, IL: Northwestern University Press.

Lewis, M. M. (1951). Infant speech, a study of the beginnings of language. New York: Humanities Press.

McNeill, D. (1970). The acquisition of language: The study of developmental psycholinguistics. New York: Harper \& Row.

Meumann, E. (1903). Die sprache des kindes. Zurich: Zurcher \& Furrer.

Miyamoto, J. (1973). Imitation and the learning of grammatical rules. In Papers from the ninth regional meeting (pp. 398-409). Chicago: Chicago Linguistics Society.

Mowrer, O. (i96o). Learning theory and the symbolic process. New York: Wiley.

Piaget, J. (1937/1954). The construction of reality in the child. New York: Basic Books.

Piaget, J. (1951/1962). Play, dreams and imitation in childhood. New York: Norton.

Preyer, W. (1882/1971). History of the development of speech, excerpt from Die sprache des kindes. In A. BarAdon \& W. Leopold (Eds.), Child language: A book of readings (pp. 29-31). Englewood Cliffs, NJ: PrenticeHall.

Ryan, J. (1973). Interpretation and imitation in early language development. In R. Hinde \& J. Stevenson-Hinde (Eds.), Constraints on learning (pp. 427-43). New York: Academic Press.

Shipley, E., Smith, C., \& Gleitman, L. (1969). A study in the acquisition of language: Free responses to commands. Language, 45, 322-42.

Sinclair, H. (1971). Sensorimotor action patterns as a condition for the acquisition of syntax. In R. Huxley \& E. Ingram (Eds.), Language acquisition: Models and methods (pp. 121-30). New York: Academic Press.

Slobin, D. (1968). Imitation and grammatical development in children. In N. Endler, L. Boulter, \& H. Osser (Eds.), Contemporary issues in developmental psychology (pp. 437-43). New York: Holt, Rinehart \& Winston.

Slobin, D. (Ed.) (1971). The ontogenesis of grammar: Some facts and several theories. New York: Academic Press. 
Smith, F., \& Miller, G. (Eds.) (1966). The genesis of language. Cambridge, MA: MIT Press.

Staats, A. (1971). Linguistic-mentalistic theory versus an explanatory S-R learning theory of language development. In D. Slobin (Ed.), The ontogenesis of grammar (pp. 103-50). New York: Academic Press.

Thorndike, E. (1913). The original nature of man. New York: Teachers College, Columbia University Press.

Valentine, C. (1930). The psychology of imitation with special reference to early childhood. Journal of Psychology, 21, 105-32. 